\section{Cureus}

Received 07/25/2016

Review began 07/27/2016

Review ended 07/27/2016

Published 08/08/2016

C) Copyright 2016

Zafar et al. This is an open access article distributed under the terms of the Creative Commons Attribution License CC-BY 3.0., which permits unrestricted use, distribution, and reproduction in any medium, provided the original author and source are credited.

\title{
Core Measures for Congestive Heart Failure in a Tertiary Care Setting in Pakistan
}

\author{
Rizwan Zafar ${ }^{1}$, Muhammad Haris ${ }^{2}$, Salman Assad ${ }^{3}$, Muhammad Usman Shabbir ${ }^{2}$, Haider \\ Ghazanfar $^{4}$, Sarah A. Malik ${ }^{1}$, Tehreem Khalid ${ }^{5}$, Ali H. Abbas ${ }^{6}$, Asad A. Saleem ${ }^{2}$ \\ 1. Department of Internal Medicine, Shifa International Hospital, Islamabad, Pakistan 2. Department of \\ Cardiology, Shifa International Hospital, Islamabad, Pakistan 3. Department of Medicine, Shifa \\ International Hospital, Islamabad, Pakistan 4. Internal Medicine, Shifa College of Medicine, Islamabad, \\ Pakistan 5. Shifa College of Medicine, Islamabad, Pakistan, Shifa International Hospital, Islamabad, \\ Pakistan 6. Department of Internal Medicine, Shifa International Hospital
}

$\square$ Corresponding author: Salman Assad, salmanassad91@gmail.com

Disclosures can be found in Additional Information at the end of the article

\section{Abstract}

Purpose: Heart failure presents a huge burden for individual patients and the healthcare system as a whole. This study aims to assess the adherence to these core measures as identified by the Joint Commission on Accreditation of Healthcare Organizations (JCAHO)/ American Heart Association (AHA) by physicians of Pakistan.

Materials and Methodology: We conducted a cross-sectional study in Shifa International Hospital, Islamabad, Pakistan from the period of April 2013 to April 2016. Patients with a primary diagnosis of heart failure were drawn from a coding section of hospital's record department. Data was evaluated to assess how strictly doctors were following core measures identified by JCAHO/AHA for the given diagnosis. Inclusion criteria for this study were patients $\geqslant 17$ years of age and patients with a primary diagnosis of heart failure according to New York Heart Association (NYHA) classification. Patients with congenital anomalies and structural heart wall problems, like sarcoidosis, hemochromatosis, and amyloidosis, were excluded from the study.

Results: Mean ejection fraction (EF) was found to be $27.23 \pm 11.72$ percent. Symptoms assessment of heart failure was done in 16/421 (3.8\%) patients according to NYHA classification and in 405/421 (96.2\%) patients according to outpatient-based heart failure assessment based on physician's experience other than NYHA classification. Left ventricle ejection fraction (LVEF) was assessed in 411/421 (97\%) patients. Out of these, 336/411 (81.7\%) patients had $\mathrm{EF}<40 \%$. Mean EF was found to be significantly higher in females as compared to males ( $\mathrm{p}<0.001)$. Three hundred and thirty-six out of $411(81.7 \%)$ patients with $\mathrm{EF}<40 \%$ needed angiotensin converting enzyme inhibitors (ACEi) and beta-blocker (BB) prescriptions. ACEi were prescribed only to 230/336 (68.7\%) patients and 248/336 (73.8\%) patients were given $\mathrm{BB}$ with documented contraindication to ACEi and BB in $7.36 \%$ and $17 \%$ patients, respectively. There was no significant association between gender and mean duration of hospitalization $(\mathrm{p}=$ 0.411). No significant association was found between $\mathrm{EF} \leqslant 40 \%$ and mean duration of hospitalization $(\mathrm{p}=0.426)$.

Conclusion: We found that symptom assessment of congestive heart failure (CHF) patients, according to NYHA guidelines, are strikingly low. Also, a significant percentage of patients who need ACEi and BB are not prescribed the required medications despite echocardiography showing low left ventricular function. 
Categories: Cardiology

Keywords: heart failure, morbidity, mortality, pakistan, chronic disease management

\section{Introduction}

Heart failure presents as a huge burden for individual patients and the healthcare system as a whole. There are an estimated 23 million people suffering from heart failure (HF) worldwide with a prevalence of $1-3 \%$. There is a $10 \%$ increase in heart failure prevalence above 65 years of age with a five-year mortality rate of up to $75 \%$ following the first hospital admission [1-2]. Despite therapeutic advancements, the prevalence of heart failure is increasing day by day, which results in great capital expenditures, deterioration of the quality of life, and mortality. The situation in Pakistan is no better as a study shows increasing numbers as well as increasing hospitalizations due to heart failure [3]. In Pakistan, no national census guidelines exist for the management of HF. Physician tends to follow already established guidelines from the American Heart Association (AHA/JCAHO) or European Cardiologists Society (ECS). Little is known about the adherence to these standard-of-care measures in tertiary care settings in Pakistan. It has been well established that adherence to these guidelines improves outcomes in CHF patients [4-5]. This study aims to assess adherence to these core measures identified by the Joint Commission on Accreditation of Healthcare Organization (JCAHO) by physicians in Pakistan [6-8].

\section{Materials And Methods}

We conducted a cross-sectional study of the patients previously treated at the Shifa International Hospital, Islamabad, Pakistan. After approval by the Institutional Review Board (IRB) of Shifa International Hospital, lists of patients discharged from cardiology and medicine wards from the period of April 2013 to April 2016 with a primary diagnosis of HF were drawn from a coding section of hospital's record department. Files were retrieved and reviewed; those meeting the eligibility criteria were included in the study. Data was evaluated to assess how strictly doctors were following core measures identified by the JCAHO/AHA for the given diagnosis. The study population included adult patients with a diagnosis of heart failure. Inclusion criteria for this study were patients $\geqslant 17$ years of age and patients with a primary diagnosis of heart failure according to NYHA classification. Patients with congenital anomalies and structural heart wall problems, like sarcoidosis, hemochromatosis, and amyloidosis, were excluded from the study.

The primary outcome was to evaluate overall hospital adherence to each and every core measure recommended by the JCAHO (Table 1). 


\section{Cureus}

\section{Core Measures - JCAHO}

HF-1: Assessment of the patient's symptoms according to NYHA classification.

HF-2: Evaluation and documentation of the left ventricular function of the patient (within last 12 months).

HF-3: Prescription of ACE inhibitors if EF < $40 \%$. (If there is any contraindication to ACE inhibitors and beta-blockers on medical grounds, then it should be documented.)

HF-4: Prescription of beta-blockers if EF < $40 \%$. (If there is any contraindication to ACE inhibitors and beta-blockers on medical grounds, then it should be documented.)

HF-5: Patient education regarding activity, diet control, drug compliance, and follow-up.

\section{TABLE 1: Core Measures by Joint Commission on Accreditation of Healthcare Organizations (JCAHO)}

$\mathrm{ACE}=$ angiotensin converting enzyme; $\mathrm{EF}=$ ejection fraction

Data were analyzed using SPSS version 21. Independent sample t-test was applied to assess whether there was any significant difference between the mean age of female and male participants. The Mann-Whitney test was used to assess for any association of gender with mean ejection fraction and mean duration of hospitalization.

\section{Results}

Total admissions in cardiology and medicine wards with a primary diagnosis of heart failure (HF) were 654 out of which 420 were eligible for the study. The mean age of the participants was found to be $66 \pm 12.5$ years. The mean age of male participants was $65.82 \pm 12.96$ years while the mean age of female participants was $66.53 \pm 11.77$ years. Independent sample t-test was applied to assess whether there was any significant difference between the mean age of female and male participants. No significant difference was found between the groups ( $p>0.05)$. Out of these, 218/420 (51.9\%) were males and 202/420 (48.1\%) were female patients. Echocardiography and left ventricular ejection fraction (LVEF) assessment were done for diagnosis in 411/420 (97.9\%) patients. Mean ejection fraction (EF) was found to be $27.23 \pm 11.72$ percent. Symptoms assessment of heart failure was done in 16/421 (3.8\%) patients according to NYHA classification and in 405/421 (96.2\%) patients according to outpatient-based heart failure assessment based on physician's experience other than NYHA classification.

Out of a total of 411 patients, 336 (81.7\%) patients had EF < 40\% and needed ACEi and BB prescriptions. Out of these 336 potential candidates, 179 (53.27\%) were given both ACEi and BB, 51 (15.17\%) patients were only given ACEi, and 69 (20.53\%) patients were only given BB. Out of 190 patients who were not prescribed ACEi, contraindication was documented in 14 (7.36\%) patients. Out of 88 patients who were not prescribed beta-blockers, contraindication was documented in 15 (17\%) patients. Four hundred and one (98.5\%) patients were given counseling and educated regarding diet, activity, and follow-up. The mean duration of hospitalization was $4.83 \pm 3.42$ days (Table 2). 


\section{Cureus}

\section{Variables}

Echocardiography done

$\mathrm{EF}<40 \%$

ACE inhibitors prescribed

ACE inhibitors contraindicated

B-blockers prescribed

B-blockers contraindicated

\section{Frequency \& Percentage}

$411 / 420(97.8 \%)$

$336 / 411(81.7 \%)$

$230 / 336(68.4 \%)$

$14 / 336(0.04 \%)$

$248 / 336(73.8 \%)$

$15 / 336(0.04 \%)$

\section{TABLE 2: Prescription of ACE Inhibitors and B-Blockers}

$\mathrm{ACE}=$ angiotensin converting enzymes; $\mathrm{EF}=$ ejection fraction; $\mathrm{B}$-blockers $=$ beta blockers

The Mann-Whitney test was used to assess for any association of gender with mean ejection fraction and mean duration of hospitalization. Mean ejection fraction was found to be significantly higher in females as compared to males $(\mathrm{p}<0.001)$. There was no significant association between gender and mean duration of hospitalization $(p=0.411)$. No significant association was found between $\mathrm{EF} \leqslant 40 \%$ and mean duration of hospitalization $(\mathrm{p}=0.426$ ) (Table 3, Figure 1).

\begin{tabular}{|c|c|c|c|}
\hline & Male & Female & P-value \\
\hline Mean Ejection Fraction & $24.0 \pm 9.924$ & $30.71 \pm 12.51$ & $<0.001$ \\
\hline Mean Duration of Stay & $5.01 \pm 3.55$ & $4.64 \pm 3.28$ & $<0.411$ \\
\hline
\end{tabular}

\section{TABLE 3: Association of Gender with Mean Ejection Fraction and Hospital Stay}




\section{Cureus}

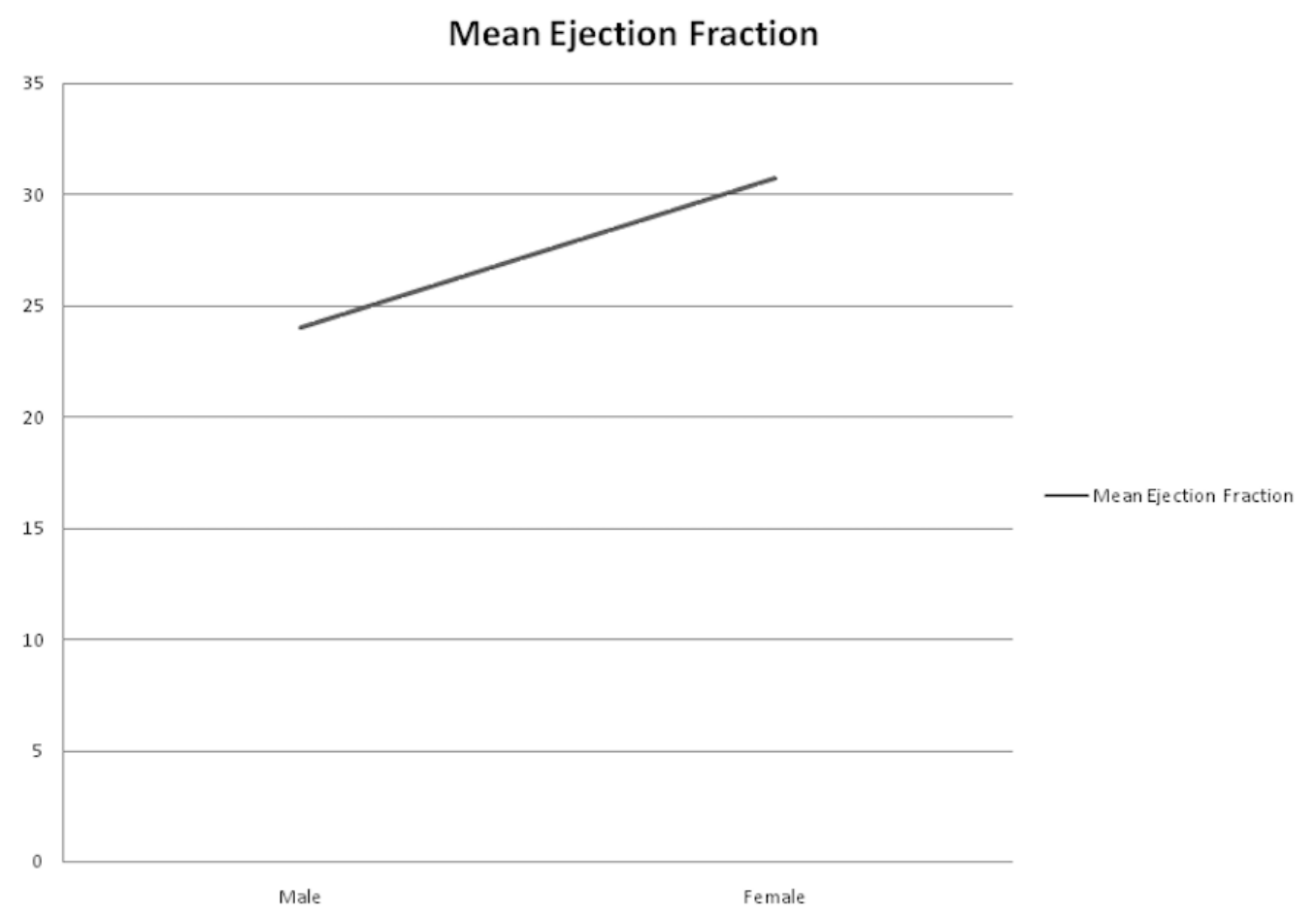

FIGURE 1: Association of Mean Ejection Fraction with Gender

\section{Discussion}

This survey showed variability in adherence to each core measure for congestive heart failure. Compliance with the assessment of symptoms according to NYHA classification was minimum probably because physicians tend to rate the symptoms by their own scoring system. Physicians should be more objective in assessing the symptoms according to the well-developed NYHA classification, so that at following visits they can use that categorization as a benchmark to see if patients are worsening, improving, or are at the same level. LVEF was assessed in the majority of the patients who were diagnosed with congestive failure. Unfortunately, a significant portion of the patients was not given ACEi and BB despite clear indication. Written discharge instructions show good adherence. Our findings are consistent with studies conducted in Western countries as poor adherence to these evidence-based measures has also been reported in the Western studies where these guidelines were formulated [9-12]. The South Asian population has a greater prevalence of coronary artery disease (CAD), which is also a leading cause of heart failure [13-14]. This fact itself emphasizes the necessity for the development of proper management planning and guidelines according to Asian population genetics, which, unfortunately, do not exist thus far. That is why it is ideal to follow AHA or European Society of Cardiology (ESC) guidelines. Although it is not known whether these guidelines are helpful in alleviating the morbidity and mortality rate in the Pakistani population, it is well established in Western countries [7-8].

Males were more likely to have decreased mean ejection fraction as compared to females. Our results were similar to a study done on Italian population, which concluded that Italian men were more likely to have reduced ejection fraction as compared to Italian women (1.59\% versus $1.5 \%$ ) [15]. According to a large multicenter study based on reduced or preserved EF heart failure, women, when compared to men, were found to be older and more likely to have hypertension, depression, or valvular heart disease and less likely to have coronary artery disease or peripheral vascular disease [16]. Valsartan in an acute myocardial infarction (MI) 
trial concluded that female patients with $\mathrm{EF}<40 \%$ who were discharged after being treated for MI were more likely to be admitted for HF during follow-up as compared to male patients [17]. A meta-analysis concluded that patients who had heart failure with preserved ejection fraction were at a lower risk of death than the patients who had heart failure with reduced ejection fraction regardless of age, gender, and etiology of cardiac failure [17]. Studies have shown that usage of ACEi is associated with improved outcomes in patients with heart failure and reduced ejection fraction [18]. The same results have not been seen in patients who have heart failure but have a preserved ejection fraction. According to the PEP-CHF randomized controlled trial, ACEi were found to have no effect on the mortality of heart failure with preserved ejection fraction [19]. A review concluded that the median prevalence of use of ACE inhibitors in patients with heart failure and reduced ejection fraction was found to be $71 \%$ in patients discharged from hospitals and $86 \%$ in patients discharged from specialty clinics [20]. In a study done in Austria by Bungard, et al., they reported that $65 \%$ of the patients with HF and reduced EF were discharged on ACE inhibitors [21]. In our study, ACE inhibitors were prescribed to $230 / 336$ (68.7\%) patients with reduced ejection fraction. Beta-blockers are one of the mainstay drugs in treating patients with heart failure and reduced ejection fraction [22]. These have been shown to significantly decrease mortality in patients with heart failure with reduced ejection fraction, most likely due to reduced detrimental effects of catecholamine stimulation on the myocardium [23]. According to the Organized Program to Initiate Lifesaving Treatment in Hospitalized HF Patients (OPTIMIZE-HF) study, the prescription rate of beta blockers at discharge was increased from $76.3 \%$ to $86.4 \%$ during the course of study while no change in the ACE inhibitor prescription rate was seen [24]. Beta-blockers were prescribed to $73.8 \%$ of the patients in our study, which is higher than the $68.7 \%$ prescription rate of ACE inhibitors.

Lack of adherence to these guidelines may be attributed to a lack of knowledge about such guidelines by Pakistan physicians as well as a failure to put this knowledge into practice. This has been depicted by a Pakistan-based study, which showed that only $92.1 \%$ of cardiologists practicing in major cities of Pakistan were aware of current guidelines of the AHA for CHF and only $87.2 \%$ said that they follow these guidelines closely [12]. Another factor that might be contributing to the poor adherence is the economic condition of the patients. Because government spending on health is very low, patients have to bear the medication cost for themselves so sometimes physicians are forced to underprescribe appropriate medications. Poor patient compliance might contribute to inadequate therapy administration [25]. According to the IMPACT-RECO survey, underprescribing of ACEi and BB was significantly associated with patients with age $>75[25]$.

\section{Strengths and weaknesses}

In Pakistan, no such data is available regarding adherence to these qualities of core measures and no clinical audit has been ever conducted on a large scale. On the other hand, it is observed in a US-based study that adherence to these measures improved over time by conducting the clinical audit in the hospital [11]. The results of this single-center tertiary care hospital-based study do not depict the overall management provided to CHF patients across Pakistan. The drawbacks of our analysis also include non-documentation of patients' compliance with dietary instructions. Also, the physicians of the institute from where the data has been obtained are mostly United States/United Kingdom-trained so they tend to follow these guidelines more often than those who are trained elsewhere in the world.

\section{Suggestions}

1. In order to decrease the morbidity and mortality in CHF patients, an awareness program should be started to ensure that these guidelines are being followed.

2. To evaluate the usefulness of these guidelines in a Pakistani population, there is a great need 
of a prospective study in a group of patients who are managed according to guidelines of $\mathrm{AHA} / \mathrm{JCAHO}$ or the ECS guidelines. It would really help in convincing physicians to recognize and adhere to globally accepted criteria for management of CHF patients.

3. An annual audit of physicians should be conducted by hospitals to let physicians know how well they are performing in accordance with the guidelines.

\section{Conclusions}

We found that symptom assessment of CHF patients according to NYHA guidelines are strikingly low and also a significant percentage of CHF patients with reduced EF are not being prescribed the required ACE inhibitors and beta blockers.

\section{Additional Information}

\section{Disclosures}

Human subjects: Consent was obtained by all participants in this study. Institutional Review Board (IRB) of Shifa International Hospital issued approval N/A. Animal subjects: All authors have confirmed that this study did not involve animal subjects or tissue. Conflicts of interest: In compliance with the ICMJE uniform disclosure form, all authors declare the following:

Payment/services info: All authors have declared that no financial support was received from any organization for the submitted work. Financial relationships: All authors have declared that they have no financial relationships at present or within the previous three years with any organizations that might have an interest in the submitted work. Other relationships: All authors have declared that there are no other relationships or activities that could appear to have influenced the submitted work.

\section{References}

1. Roger VL: Epidemiology of heart failure. Circ Res. 2013, 113:646-59. 10.1161/CIRCRESAHA.113.300268

2. Sahle BW, Owen AJ, Mutowo MP, Krum H, Reid CM: Prevalence of heart failure in Australia: a systematic review. BMC Cardiovasc Disord. 2016, 16:32. 10.1186/s12872-016-0208-4

3. Noor L, Adnan Y, Khan SB, Shah SS, Sawar S, Qadoos A, Arif M, Awan ZA: Inpatient burden of heart failure in the cardiology units of tertiary care hospitals in Peshawar. Pak J Physiol. 2012, 8:3-6.

4. Jessup M, Abraham WT, Casey DE, Feldman AM, Francis GS, Ganiats TG, Konstam MA, Mancini DM, Rahko PS, Silver MA, Stevenson LW, Yancy CW: 2009 focused update:

ACCF/AHA Guidelines for the Diagnosis and Management of Heart Failure in Adults: a report of the American College of Cardiology Foundation/American Heart Association Task Force on Practice Guidelines: developed in collaboration with the International Society for Heart and Lung Transplantation. Circulation. 2009, 119:1977-2016.

10.1161/CIRCULATIONAHA.109.192064

5. Hunt SA, Abraham WT, Chin MH, Feldman AM, Francis GS, Ganiats TG, Jessup M, Konstam MA, Mancini DM, Michl K, Oates JA, Rahko PS, Silver MA, Stevenson LW, Yancy CW: ACC/AHA 2005 guideline update for the diagnosis and management of chronic heart failure in the adult: summary article: a report of the American College of Cardiology/American Heart Association Task Force on Practice Guidelines (Writing Committee to Update the 2001 Guidelines for the Evaluation and Management of Heart Failure). J Am Coll Cardiol. 2005, 46:1116-43. 10.1016/j.jacc.2005.08.023

6. Fonarow GC, Abraham WT, Albert NM, Stough WG, Gheorghiade M, Greenberg BH, O'Connor CM, Pieper K, Sun JL, Yancy C, Young JB; OPTIMIZE-HF Investigators and Hospitals: Association between performance measures and clinical outcomes for patients hospitalized with heart failure. JAMA. 2007, 297:61-70. 10.1001/jama.297.1.61

7. Patel UD, Hernandez AF, Liang L, Peterson ED, LaBresh KA, Yancy CW, Albert NM, Ellrodt G, 
Fonarow GC: Quality of care and outcomes among patients with heart failure and chronic kidney disease: A Get With the Guidelines -- Heart Failure Program study. Am Heart J. 2008, 156:674-81. 10.1016/j.ahj.2008.05.028

8. Yancy CW, Fonarow GC, Albert NM, Curtis AB, Stough WG, Gheorghiade M, Heywood JT, McBride ML, Mehra MR, O'Connor CM, Reynolds D, Walsh MN: Adherence to guidelinerecommended adjunctive heart failure therapies among outpatient cardiology practices (findings from IMPROVE HF). Am J Cardiol. 2010, 105:255-60. 10.1016/j.amjcard.2009.08.681

9. Williams SC, Schmaltz SP, Morton DJ, Koss RG, Loeb JM: Quality of care in U.S. hospitals as reflected by standardized measures, 2002-2004. N Engl J Med. 2005, 353:255-64. 10.1056/NEJMsa043778

10. Gupta M, Singh N, Verma S: South Asians and cardiovascular risk: what clinicians should know. Circulation. 2006, 113:e924-29. 10.1161/CIRCULATIONAHA.105.583815

11. Joshi P, Islam S, Pais P, Reddy S, Dorairaj P, Kazmi K, Pandey MR, Haque S, Mendis S, Rangarajan S, Yusuf S: Risk factors for early myocardial infarction in South Asians compared with individuals in other countries. JAMA. 2007, 297:286-94. 10.1001/jama.297.3.286

12. Shoukat S, Gowani SA, Taqui AM, Ul Hassan R, Bhutta ZA, Malik AI, Sherjeel SA, Sheheryar Q, Dhakam SH: Adherence to the European Society of Cardiology (ESC) guidelines for chronic heart failure--a national survey of the cardiologists in Pakistan. BMC Cardiovasc Disord. 2011, $11: 68.10 .1186 / 1471-2261-11-68$

13. Yancy CW, Fonarow GC, Albert NM, Curtis AB, Stough WG, Gheorghiade M, Heywood JT, McBride ML, Mehra MR, O'Connor CM, Reynolds D, Walsh MN: Influence of patient age and sex on delivery of guideline-recommended heart failure care in the outpatient cardiology practice setting: findings from IMPROVE HF. Am Heart J. 2009, 157:754-62.e2. 10.1016/j.ahj.2008.12.016

14. Kasje WN, Denig P, Stewart RE, de Graeff PA, Haaijer-Ruskamp FM: Physician, organisational and patient characteristics explaining the use of angiotensin converting enzyme inhibitors in heart failure treatment: a multilevel study. Eur J Clin Pharmacol. 2005, 61:145-51. 10.1007/s00228-005-0897-6

15. Buja A, Solinas G, Visca M, Federico B, Gini R, Baldo V, Francesconi P, Sartor G, Bellentani M, Damiani G: Prevalence of heart failure and adherence to process indicators: Which sociodemographic determinants are involved?. Int J Environ Res Public Health. 2016, 13:238. 10.3390/ijerph13020238

16. Hsich EM, Grau-Sepulveda MV, Hernandez AF, Peterson ED, Schwamm LH, Bhatt DL, Fonarow GC: Sex differences in in-hospital mortality in acute decompensated heart failure with reduced and preserved ejection fraction. Am Heart J. 2012, 163:430-437.e3. 10.1016/j.ahj.2011.12.013

17. Lewis EF, Velazquez EJ, Solomon SD, Hellkamp AS, McMurray JJ, Mathias J, Rouleau JL, Maggioni AP, Swedberg K, Kober L, White H, Dalby AJ, Francis GS, Zannad F, Califf RM, Pfeffer MA: Predictors of the first heart failure hospitalization in patients who are stable survivors of myocardial infarction complicated by pulmonary congestion and/or left ventricular dysfunction: a VALIANT study. Eur Heart J. 2008, 29:748-56. doi: 10.1093/eurheartj/ehn062

18. Meta-analysis Global Group in Chronic Heart Failure (MAGGIC): The survival of patients with heart failure with preserved or reduced left ventricular ejection fraction: an individual patient data meta-analysis. Eur Heart J. 2012, 33:1750-57. 10.1093/eurheartj/ehr254

19. Mujib M, Patel K, Fonarow GC, Kitzman DW, Zhang Y, Aban IB, Ekundayo OJ, Love TE, Kilgore ML, Allman RM, Gheorghiade M, Ahmed A: Angiotensin-converting enzyme inhibitors and outcomes in heart failure and preserved ejection fraction. Am J Med. 2013, 126:401-10. 10.1016/j.amjmed.2013.01.004

20. Cleland JG, Tendera M, Adamus J, Freemantle N, Polonski L, Taylor J; PEP-CHF Investigators: The perindopril in elderly people with chronic heart failure (PEP-CHF) study . Eur Heart J. 2006, 27:2338-45. 10.1093/eurheartj/ehl250

21. Bungard TJ, McAlister FA, Johnson JA, Tsuyuki RT: Underutilisation of ACE inhibitors in patients with congestive heart failure. Drugs. 2001, 61:2021-33. 10.2165/00003495200161140-00002

22. Marzluf BA, Reichardt B, Neuhofer LM, Kogler B, Wolzt M: Influence of drug adherence and medical care on heart failure outcome in the primary care setting in Austria. Pharmacoepidemiol Drug Saf. 2015, 24:722-30. 10.1002/pds.3790 


\section{Cureus}

23. Li SJ, Sartipy U, Lund LH, Dahlström U, Adiels M, Petzold M, Fu M: Prognostic significance of resting heart rate and use of $\beta$-blockers in atrial fibrillation and sinus rhythm in patients with heart failure and reduced ejection fraction: Findings from the Swedish Heart Failure Registry. Circ Heart Fail. 2015, 8:871-79. 10.1161/CIRCHEARTFAILURE.115.002285

24. Hunt SA, Abraham WT, Chin MH, Feldman AM, Francis GS, Ganiats TG, Jessup M, Konstam MA, Mancini DM, Michl K, Oates JA, Rahko PS, Silver MA, Stevenson LW, Yancy CW: 2009 focused update incorporated into the ACC/AHA 2005 Guidelines for the Diagnosis and Management of Heart Failure in Adults. A report of the American College of Cardiology Foundation/American Heart Association Task Force on Practice Guidelines: developed in collaboration with the International Society for Heart and Lung Transplantation. Circulation. 2009, 119:e391-479. 10.1161/CIRCULATIONAHA.109.192065

25. de Groote P, Isnard R, Assyag P, Clerson P, Ducardonnet A, Galinier M, Jondeau G, Leurs I, Thébaut JF, Komajda M: Is the gap between guidelines and clinical practice in heart failure treatment being filled? Insights from the IMPACT RECO survey. Eur J Heart Fail. 2007, 9:1205-11. 10.1016/j.ejheart.2007.09.008 